\title{
Mitral valve disease and open heart surgery in osteogenesis imperfecta tarda
}

\author{
S. J. Wood, J. Thomas, and M. V. Braimbridge \\ From the Department of Cardiothoracic Surgery, St. Thomas' Hospital, London
}

Two patients are described with mitral valve disease associated with osteogenesis imperfecta. The mitral valve showed the typical pathology associated with this condition - the prolapsed cusps and ruptured chordae. Both valves were operated on with cardiopulmonary bypass with the expected postoperative haemorrhagic problems. Both, however, left hospital satisfactorily.

Cardiovascular anomalies are well recognized in Marfan's syndrome (McKusick, 1960) and in EhlersDanlos syndrome, and have been described in association with osteogenesis imperfecta (Criscitiello et al., 1965). Surgery carried out on patients with osteogenesis is liable to be complicated by severe postoperative problems (Woolley, Morgan, and Hays, 1967); and cardiopulmonary bypass and mitral valve surgery have not previously been described in such patients. The diagnosis of osteogenesis imperfecta is based on the family history and the association of blue sclerae, skeletal abnormalities, deafness, poor teeth, and multiple fractures.

\section{Case reports}

Case I

A 49-year-old man sustained multiple fractures of his upper limbs as a child. (His daughter had blue sclerae, and had suffered multiple fractures also.) Renal calculi formed, which were removed on the right in 1954 and on the left in 1962 . When he was 18 he fractured both femurs. He had no history of rheumatic fever.

In 1969 he developed pleuritic pain and dyspnoea, diagnosed as pulmonary embolism. A murmur was heard, and treatment with anticoagulants started. He remained dyspnoeic, however, with an exacerbation in 1970. On admission he was very dyspnoeic (NYHA grade 3), but had no orthopnoea or paroxysmal nocturnal dyspnoea. On examination he had blue sclerae, embryotoxon, and a detached retina in the right eye. His face was triangular in shape with prominent ears and occipital bossing, and he had bilateral deafness. $\mathrm{He}$ was in sinus rhythm, with a blood pressure of $130 / 85 \mathrm{mmHg}$ and there was a $2 \mathrm{~cm}$ ' $v$ ' wave in the jugular venous pressure. He had moderate left and right ventricular hypertrophy with a palpable pulmonary second sound. On auscultation at the mitral

Received 13 July 1972. area there was a soft mitral first sound, a loud pansystolic murmur and thrill radiating to the axilla, a soft third sound, and a short diastolic murmur. Moderate accentuation of the pulmonary second sound was heard.

His electrocardiogram showed sinus rhythm, with a PR interval of $0.24 \mathrm{sec}$, a $Q R S$ axis of $+60^{\circ}$, and no

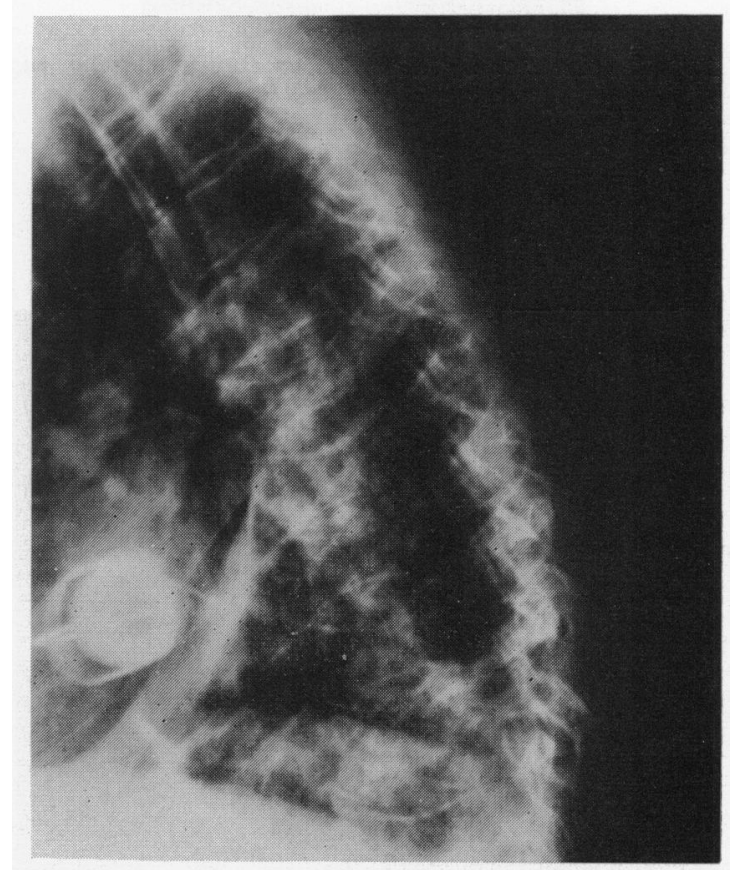

FIG. I Case I. Postoperative lateral chest x-ray to show prosthetic mitral valve and 'codfish' deformity of spine (porosis and hourglass appearance of vertebrae). 


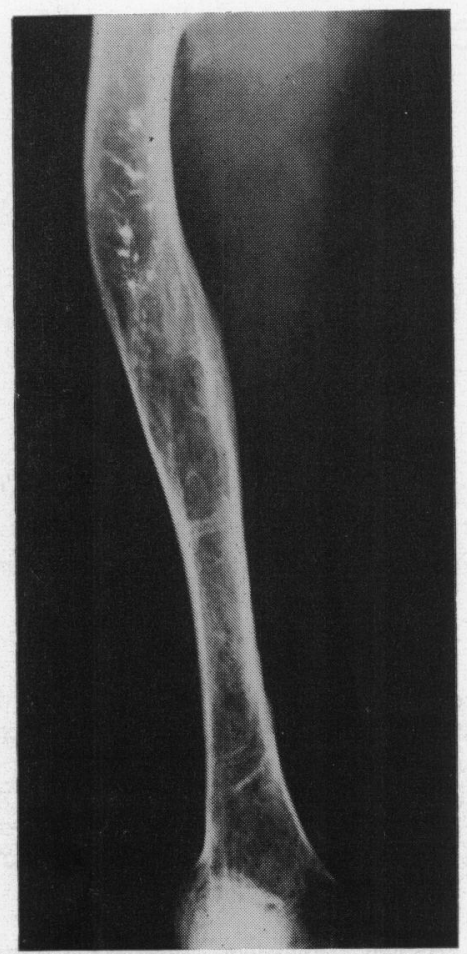

FIG. 2 Case I. Femur showing typical bowing and old fractures.

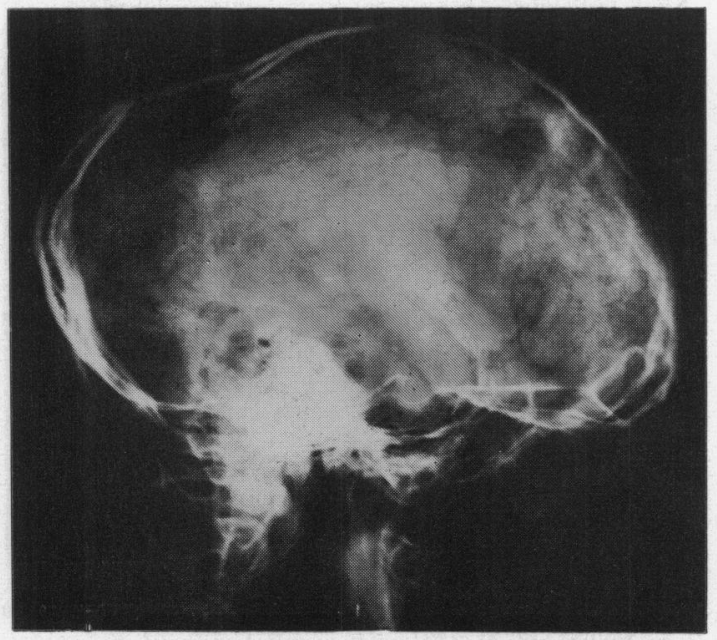

FIG. 3 Case I. Skull x-ray showing typical 'overhanging occiput'. ventricular hypertrophy. Chest $x$-ray showed moderate enlargement of the ventricular mass (cardiothoracic ratio 167/275) and slight enlargement of the pulmonary artery, left atrium, and right atrium. His spine showed a 'codfish' deformity of the vertebrae with scoliosis (Fig. I), and there were healed fractures of both femurs (Fig. 2). There was a staghorn calculus in his right renal pelvis. The skull $x$-ray showed the typical 'overhanging occiput' of osteogenesis imperfecta (Fig. 3).

At cardiac catheterization the mean pulmonary capillary venous pressure was $22 \mathrm{mmHg}$, with a ' $\mathrm{v}$ ' wave of $30 \mathrm{mmHg}$. The end-diastolic pressure in the left ventricle was $15 \mathrm{mmHg}$. The pulmonary artery pressure was 42 to $52 / 27 \mathrm{mmHg}$, the aorta was $125 / 60 \mathrm{mmHg}$, and the left ventricular pressure was $115 / 0$ to $15 \mathrm{mmHg}$. At angiography mitral regurgitation was considerable and the left ventricle contracted well.

Blood investigation showed a serum calcium of 10.4 $\mathrm{mg} / \mathrm{roO} \mathrm{ml}$ and an inorganic phosphate of $3.5 \mathrm{mg} / \mathrm{ml}$. The haemoglobin, white cells, and platelet count $\left(260,000 / \mathrm{mm}^{3}\right)$ were normal: the platelet morphology was normal. Further tests of platelet function were not carried out as the patient was anticoagulated with warfarin.

At operation in March 1972 the mitral valve ring was very dilated, the cusps large, with the anterior leaflet overriding the posterior and with one ruptured chorda on the medial side of the anterior leaflet. There were anomalous papillary muscles, of small size, attached to the sides of the left ventricle. There was no evidence of previous rheumatic fever. The mitral valve was excised and a No. 46320 Starr ball valve prosthesis sutured to the fragile valve ring with interrupted sutures (42).

The left atrium was closed with difficulty due to the friable tissue and there was further difficulty in obtaining haemostasis from the sternotomy wound.

After operation he was maintained on intermittent positive pressure respiration for two days. On the sixth day he suddenly deteriorated and his right thigh started to swell. He was returned to theatre and a litre of clot was evacuated and a branch of the superficial pudendal artery ligated, which had been punctured at the time of Seldinger femoral cannulation for pressure monitoring at operation. Maintenance of a diuresis to prevent renal failure in association with his renal calculus caused an episode of dehydration which was corrected with saline transfusion. His wound healed well, but he needed much encouragement to become mobile. At follow-up three months later he was much improved with minimal dyspnoea but was still not fully mobile and attended in a wheelchair.

\section{Case 2}

A 63-year-old man was asymptomatic until 1970 when he suddenly became short of breath, orthopnoeic, and noticed palpitations. He then had an attack of paroxysmal nocturnal dyspnoea and was admitted to hospital for medical treatment of his heart failure. After this his effort intolerance was moderate (NYHA 2) and he suffered further attacks of paroxysmal nocturnal dyspnoea. He had no history of rheumatic fever.

At school he fractured both wrists and later his left 
elbow. He had diverticulitis and in 1957 had an operation for perforation of a colonic diverticulum. His father had frequent fractures, was very deaf, and had blue sclerae.

On examination he was of normal build with blue sclerae and was deaf in the left ear. He was in sinus rhythm, with a blood pressure of $130 / 80 \mathrm{mmHg}$ and his jugular venous pressure was not raised. He had left ventricular hypertrophy and an apical systolic thrill. At the mitral area, he had a loud pansystolic murmur and at the aortic area a soft aortic regurgitant murmur.

He had gross limitation of movement of both elbows, his wrists were deformed, and his fingers showed obvious ulnar deviation but little swelling of the synovium.

His electrocardiogram showed sinus rhythm with a PR interval of $0.20 \mathrm{sec}$, a QRS axis of $0^{\circ}$, and slight left ventricular hypertrophy. Chest radiography showed scoliosis and slight enlargement of the left atrium and ventricular mass. The cardiothoracic ratio was $165 /$ 295. At cardiac catheterization, the mean pulmonary capillary venous pressure had a ' $v$ ' wave of $17 \mathrm{mmHg}$, and the left ventricular end-diastolic pressure was 9 mmHg. Angiography showed severe mitral regurgitation, a moderately enlarged left atrium, and a very dilated left ventricle.

Though this patient stated that he 'bled easily', he had undergone previous operations without undue haemorrhage, and the following tests were normal: haemoglobin, white cell count, platelets $\left(2 \mathrm{I}, 000 / \mathrm{mm}^{3}\right.$ with normal morphology), prothrombin time ratio $I \cdot I$, and kaolin activated partial thromboplastin time 31.5 sec (control $35.4 \mathrm{sec}$ ). The Ivy bleeding time, $4 \mathrm{~min} 15$ $\mathrm{sec}$, clot retraction and glass bead column adhesion, 2 I per cent, were normal. His serum calcium was $9 \cdot$ I $\mathrm{mg} / 100 \mathrm{ml}$ and his inorganic phosphate was $3 \mathrm{mg} / 100 \mathrm{ml}$.

At operation in May 1972 the tissues were friable and bled easily. Cardiopulmonary bypass was used without hypothermia. The mitral valve showed a very redundant posterior cusp with attenuated chordae, two of which had ruptured and there was a tear in the posterior leaflet I cm long. A modified McGoon valvoplasty was performed, plicating the posterior cusp and obliterating the ruptured chordae and the tear, carrying the plication onto the left atrium (Brown et al., 1968). The left atrium was very flimsy and general haemostasis proved extremely difficult. It was recognized that such a valvoplasty was not usually curative in patients with redundant cusps and that some regurgitation would persist. He was, however, 63, with diverticula of the colon which might bleed, and a history of bleeding which made valve replacement and subsequent anticoagulation undesirable.

Initially chest drainage was considerable, he developed haematomata at venepuncture sites and also haematuria, but the chest drains could be removed after two days and the haematuria resolved. One month later his dyspnoea was minimal but he had developed melaena, probably from his diverticular disease. He was not on anticoagulants.

\section{Discussion}

Osteogenesis imperfecta presents to the cardiac surgeon because of the known association of dilated aortic and mitral valve rings and redundant cusps of the mitral valve. Operation on such patients is likely to be complicated by haemorrhage, poor tissue healing, and difficulties in ambulation.

Aneurysmal defects of the mitral valve have been described in osteogenesis imperfecta as has dilatation of the aortic root (Criscitiello et al., 1965). The first patient described here had a dilated mitral valve ring, rather voluminous cusps with the anterior overriding the posterior, and one ruptured chorda of the anterior leaflet. He also had anomalous papillary muscles of small size, attached to the side of the ventricle. The second patient had redundant cusps of the mitral valve and ruptured posterior chordae. He also had aortic regurgitation with cusps that were normal on palpation. Neither gave any history of rheumatic fever, neither did the macroscopical appearances nor histological examination of the cusps show any evidence of it. These two cases suggest that stretching and deformity of the leaflets of the mitral valve had occurred; this has been described as a manifestation of this collagen disorder, as well as the dilatation of the aorta as in Case 2. The first patient was treated by valve replacement with a large number of sutures in the flimsy mitral valve ring to prevent dehiscence of the valve. In the second patient the redundant posterior cusp was plicated to avoid suturing a valve prosthesis into the weak tissue of the valve ring. He was 63 , with diverticula of the colon, had less severe symptoms, and had a possible bleeding disorder which it was hoped would be little exaggerated by a short bypass operation without hypothermia.

Osteogenesis imperfecta is not usually thought of as a bleeding disorder, but occasionally haemorrhage is a prominent feature of the disease (Harrington, 1957). Epistaxes, melaena, haematomata, subconjunctival and preretinal haemorrhages have been described (Gautier and Guinand-Doniol, 1952). These may result from poor support of blood vessels due to lack of normal adult collagen (Follis, 1953). However, qualitative platelet defects have also been described, including impaired clot retraction and prolonged thromboplastin generation time (Gautier and Guinand-Doniol, 1952; Siegel, Friedman, and Schwartz, 1957; Brody, Altman, and Kimball, 1963) and more recently abnormalities of platelet morphology (Estes, 1968) and failure of platelet factor 3 release and impaired ADP aggregation (Hathaway, Solomons, and Ott, 1972).

Neither of the patients described had clinical or laboratory evidence of a haemostatic defect before operation, but in both haemostasis was difficult and prolonged after cardiopulmonary bypass. The first developed a large haematoma in the thigh, and the 
second had multiple haematomata, haematuria, and a subsequent melaena when not on anticoagulants. It was not clear how much of the bleeding was due to defective platelet function and how much to friable connective tissue with poor collagen.

Wound healing is another problem in osteogenesis imperfecta, weak, wide scars being common (McKusick, 1960). In the two patients described, however, the wound healed well. In both cases the left atrium was especially flimsy for suturing, and in the first Teflon felt buttresses had to be used to prevent the sutures cutting through the friable tissue.

Mobilization of a patient who has had multiple fractures and is then confined to bed for a considerable period can be difficult, and this proved to be so in the first patient whose period of confinement to bed was prolonged by the development of a haematoma in the thigh. He was not fully mobile when seen as an outpatient three months after operation, being brought in in a wheelchair.

Our grateful thanks are due to Dr. G. de J. Lee, The Radcliffe Infirmary, Oxford; and to Dr. D. W. Evans, Papworth Hospital, Cambridgeshire, for permission to publish their cases.

\section{References}

Brody, J. I., Altman, D. H., and Kimball, S. G. (1963). Mesenchymal dysplasia with impaired thromboplastin generation. Archives of Internal Medicine, III, 784.
Brown, A. H., Braimbridge, M. V., Clement, A. J., Sabar, E., and Mendel, D. (I968). Valvoplasty for abnormality of the posterior (mural) cusp of the mitral valve. Thorax, 23, 608.

Criscitiello, M. G., Ronan, J. A., Besterman, E. M. M., and Schoenwetter, W. (1965). Cardiovascular abnormalities in osteogenesis imperfecta. Circulation, 31, 255.

Estes, J. W. (I968). Platelet size and function in the heritable disorders of connective tissue. Annals of Internal Medicine, 68, 1237.

Follis, R. H., Jr. (1953). Maldevelopment of the corium in the osteogenesis imperfecta syndrome. Bulletin of the fohns Hopkins Hospital, 93, 225.

Gautier, P., and Guinand-Doniol, J. (1952). Un cas de maladie de Lobstein associée à une thrombasthenie héréditaire et familiale de Glanzmann. Bulletins et Mémoires de la Société Médicale des Hôpitaux de Paris, 68, 577.

Harrington, W. J. (1957). The Purpuras. Disease-a-Month. Year Book Medical Publishers, Chicago.

Hathaway, W. E., Solomons, C. C., and Ott, J. E. (1972). Platelet function and pyrophosphates in osteogenesis imperfecta. Blood, 39, 500 .

McKusick, V. A. (1960). Hereditable Disorders of Connective Tissue, and ed. C. V. Mosby, St. Louis.

Siegel, B. M., Friedman, I. A., and Schwartz, S. O. (1957). Haemorrhagic disease in osteogenesis imperfecta. Study of platelet functional defect. American fournal of Medicine, 22, 315.

Woolley, M. M., Morgan, S., and Hays, D. M. (1967). Hereditable disorders of connective tissue. Surgical and anesthetic problems. Fournal of Pediatric Surgery, 2, 325.

Requests for reprints to M. V. Braimbridge, Esq., F.R.C.S., Cardiothoracic Unit, St. Thomas' Hospital, London SEI ${ }_{7} \mathrm{EH}$. 